\title{
Distance Control and Positive Security for Intrinsic Equipment Working in Explosive Potential Atmospheres
}

\author{
Emil Pop, Gabriel-Ioan Ilcea, Ionut-Alin Popa \\ Control Engineering, Computers, Electrical Engineering and Power Engineering, University of Petroșani, Petroșani, Romania \\ Email: EmilPop@upet.ro,gabrielilcea@upet.ro, ionutalin_popa@yahoo.ro
}

How to cite this paper: Pop, E., Ilcea, G.-I. and Popa, I.-A. (2018) Distance Control and Positive Security for Intrinsic Equipment Working in Explosive Potential Atmospheres. Engineering, 10, 75-84. https://doi.org/10.4236/eng.2018.103006

Received: December 12, 2017

Accepted: March 13, 2018

Published: March 16, 2018

Copyright $\odot 2018$ by authors and Scientific Research Publishing Inc. This work is licensed under the Creative Commons Attribution International License (CC BY 4.0).

http://creativecommons.org/licenses/by/4.0/

\begin{abstract}
In this paper, intrinsic safety and positive security distance control for an up/down elevator which extracts the materials from an underground coal mine is approached. For a better understanding of intrinsic safety and positive security, the first part of the paper describes the potential risk the workers are facing while working in dangerous environments like coal mining with "grisou" atmospheres and what the conditions of an unfortunate event to take place are. We presented the diagram and working principle for intrinsic safety equipment used in potential explosive areas based on which we modeled and simulated the intrinsic and positive security distance control in order to get a software solution for it. We created an algorithm and simulated the process in Matlab Simulink. The simulation results done in Matlab Simulink were then entered into a Moeller PLC using a ladder-type programming language. For protection against explosive atmospheres, the PLC is inserted into a metal housing with intrinsic protection and Positive Security.
\end{abstract}

\section{Keywords}

Fire Triangle, Distance Control, Positive Security, Explosion Risk, Intrinsic Safety

\section{Fire Triangle}

In many situations people work in a space with aggressive atmosphere regarding a potential risk of explosion. We can enumerate some sectors of activates as: pacification, military, chemistry, mining, petroleum and gaze etc. Difficult situations exist in underground coal mining where a mixture between air (oxygen), methane and/or carbon-dust produces so called "grisou" which can explode at a sample flame or sparkle. But some atmosphere with hydrogen or acetylene, like in pe- 
troleum and gas activities, can be more aggressive [1]. Other very dangerous situation is for people working in closed space where the power of explosion increases [2]. For the people safeties, it must analyze if a risk of explosions exists or not in this location by evaluating three conditions:

- There is an atmosphere with enough oxygen to maintain the flame and explosion;

- There are easily inflammable substances in the location;

- There are or there can appear energy sources which can initiate explosions.

The three conditions define the so called Fire triangle, Figure 1.

First two conditions define the existence of Explosive potential atmosphere. All tree conditions define the existence of Risk of explosion.

Presence of some substances transforms a normal location in one with a Potential explosive atmosphere: gazes (butane, propane, acetylene, methane, carbon monoxide etc.), inflammable liquid (petrol fuels, oils, chemical solvents etc.) and inflammable dusty (coal, wood, sugar, flour, cereals), plastic materials etc.

Presence of some ignition energy sources transforms a potential explosive atmosphere in a location with risk of explosions: hot surfaces, flames and hot gazes, mechanical and electrical sparkles, electrical equipment, static electricity, electromagnetic waves, exothermic reactions etc. Explosion risks safety is assured by technological and management resources. So, electrical equipments are specially manufactured to be anti-explosive and for mining industry anti-deflagrate [3]. An important category of equipment which is safe from any source of explosion risk is called with intrinsic safety which must have positive security too [4].

\section{Intrinsic Safety and Positive Security Equipment}

Many explosions were initiated by the electrical equipment and unfortunately this risk exists still now. A good solution was developed in the last decade, named intrinsic safety, which consists of designing the equipment in such a way that they can't produce an explosion [5].

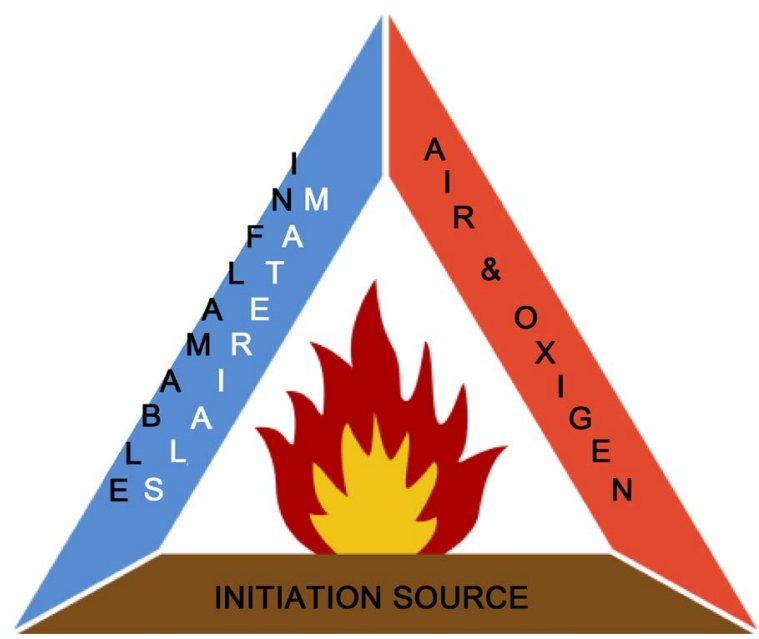

Figure 1. Fire triangle. 
Regarding the intrinsic security equipment, we use the following concepts:

- Potentially explosive atmosphere-Is an area where a mixture of inflammable gases and oxygen exists in a percentage adequate for explosion;

- Initiation source-Is an action which produces enough energy capable to ignite the potentially explosive atmosphere;

- Intrinsic safety-Represent a level of safety for electric equipment which in normal function or in defect state, the energy in the circuit is limited to such values that do not allow the creation of high temperatures and/or ignition sparks, respectively electric arc to initiate the Explosive potential atmosphere [6];

- Anti-explosive/Anti deflagrate-Represents a level of safety which an electric equipment is enclosed in a special housing so in normal function or in defect state it cannot transmit to outside enough energy to initiate the potentially explosive atmosphere [7];

- Safety area-Is a zone where the explosion cannot be transmitted outside to initiate explosions in a potentially explosive atmosphere;

- Hazardous area-Is a zone where there is a potentially explosive atmosphere;

- Security barrier-Is a module which makes the inputs/ outputs become intrinsic safety;

- Positive security-Is a quality of an input which is supervised and in case of malfunction of it generates a stop signal of the process. Positive security is not related to intrinsic safety. This can be considered as a protection that overrides the entry rather than the process;

- A hazardous area is a dangerous area presenting a risk for explosions. To assure a safety for a person which works in a dangerous area, the electric equipment must be built to be anti-explosive/anti-deflagrate [8].

Connection between this equipment must be made with intrinsic safety and positive security input/output. For this reason, in the equipment there is a security (safety) barrier which insolates the hazardous area from the safety zone, Figure 2.

If a safety zone is created using a special enclosed carcass, the input and output is connected to the safety barrier, as in the next figure.

Intrinsic output can be used as passive element (without energy), for example as electric contact, but input may have low energy to be intrinsic safety [9].

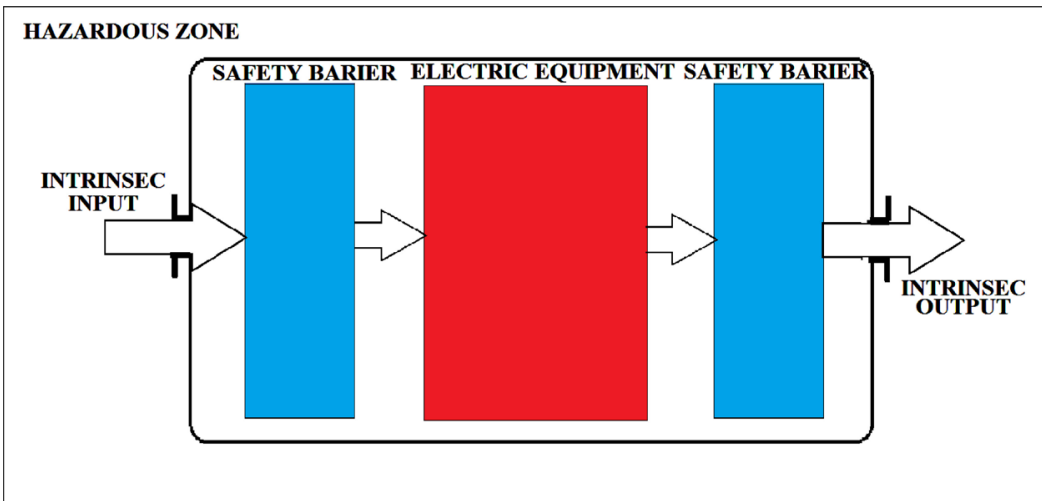

Figure 2. Principle of intrinsic safety equipment. 
In some cases, like in underground mining for example, it is used an electronic distance control device connected by cable with a passive button, with intrinsic safety, positive security and minimum conductors in cable.

Many distance control devices work by the principle presented in Figure 3 using current resonant transformer in series with an a.c/d.c. discriminator which supply a d.c. relay with constant hysteresis cycle. If the n.o. button is ON, d.c. flows current through the distance cable and the resonant transformer delivers a maximum current to y relay, which commutates its contacts (y-no, y-nc). This command is memorized by a resistance in parallel with n.o. button and hysteresis cycle. If the cable is shortcut, an a.c. flow current supplies the relay and it gets disconnected [10].

In the next section we model and simulate this kind of distance control in order to get a software solution for it.

\section{Modeling Simulation Algorithm and Software Solution for Intrinsic Safety Control}

The principle of distance control presented above is hardware oriented with many disadvantages and high costs. For new equipments with software embedded is use microprocessors or in other situations PLCs [11] [12]. In this case a software solution can cover all the requirements of these devices therefore the hardware solution cannot be accepted. In this case a software solution can cover all of the requirements of this device [13]. To see if it is possible to model and simulate the hardware [14], a solution is presented as showed in Figure 4.

If n.o. switch is on resonant transformer deliver maximum current, as in Figure 4(b), and by a.c/d.c bloc the relay is on. This state is memorized by shunt resistance and hysteresis cycle of relay. Only by pushing the n.c. button the current outside of hysteresis cycle is reduced and the relay is off. The same situation appears if the cable is cut or shortcut, which disconnects the relay and brings the

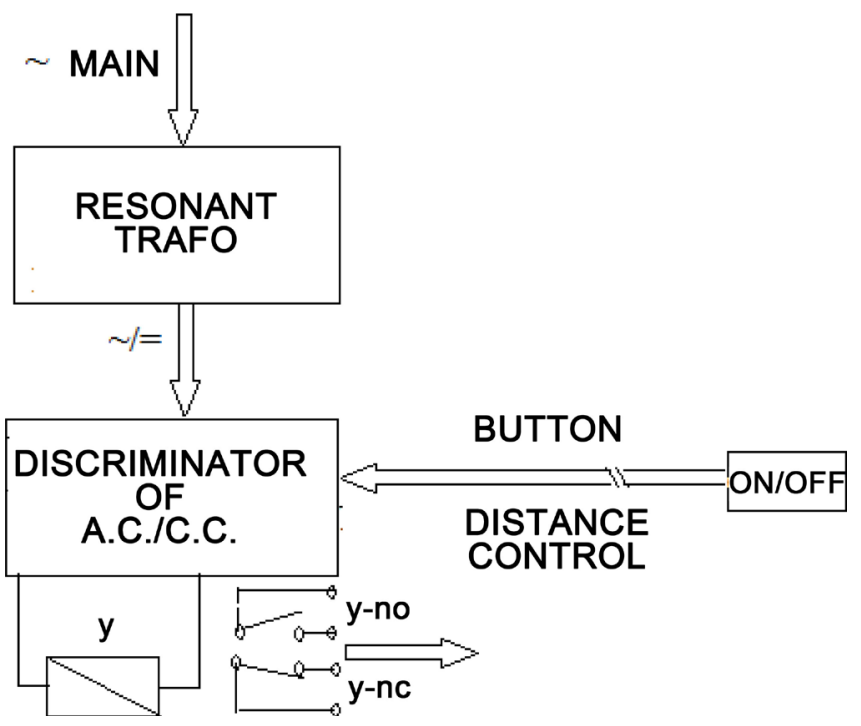

Figure 3. Intrinsic safety and positive security distance control bloc diagram. 


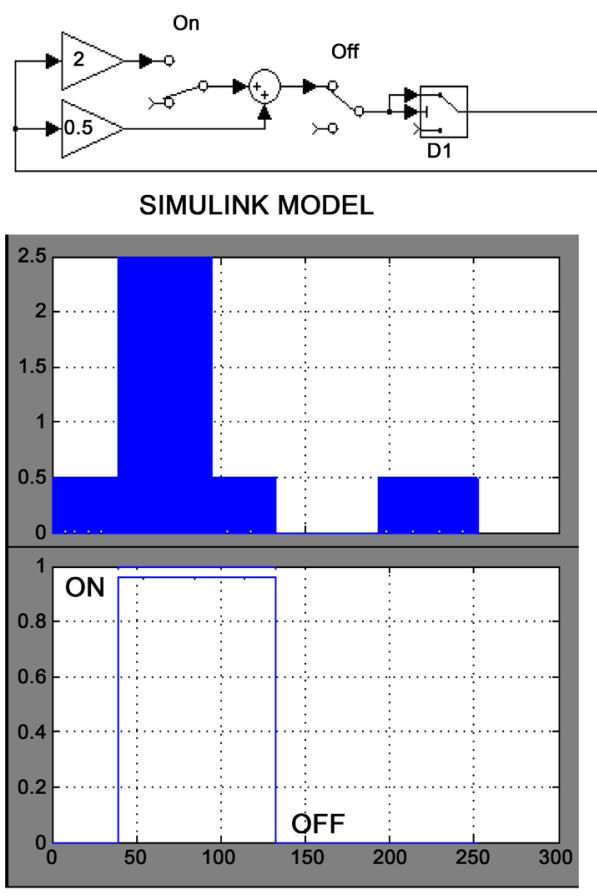

SIMULATION RESULTS
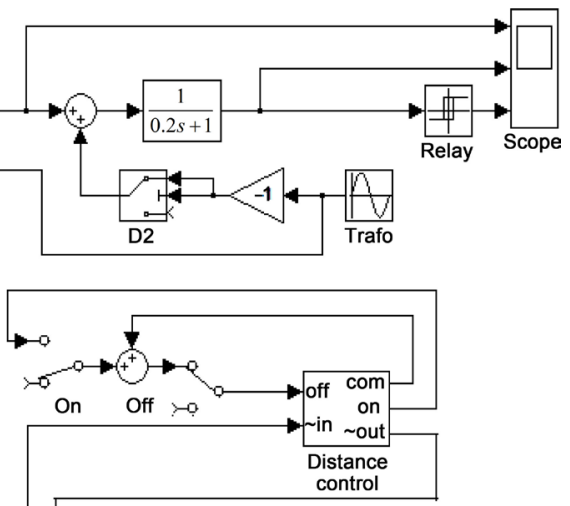

SIMULATION BLOCK

Figure 4. Modeling and simulation results of intrinsic and positive security distance control.

equipment to stop position [15].

This device assures the following conditions:

- Input and output have the security barriers to be of intrinsic security;

- The distance connection cable between on/off button and device uses only two conductors ;

- The device has positive security that is useful in mines: if the connection cable is cat or shortcut the device is set in stop state.

The simulation results open a possibility to design the device using the software solution for positive security generated by cable, a sample code for start and stop, and also uses security barriers for assuring the intrinsic safety [16].

The device ensures the following conditions:

- Intrinsic safety;

- Positive security;

- The distance connection cable is made with only two conductors;

- No resonant transformer and other hardware;

- A single button is used for on/off control;

- Software is integrated in equipment or in PLC.

In Figure 5 is presented the algorithm to design the software and ladder program of it [17] [18].

The software simulates two counters CC1, CC2 and an on delay timing relay TT1, which retriggers the input in a controlled interval time (0.5 - $1.2 \mathrm{~s})$. Input signal is generated by a normally closed button on falling age. If the number of signals is three (3) the output Q becomes ON, otherwise it falls in OFF state or 


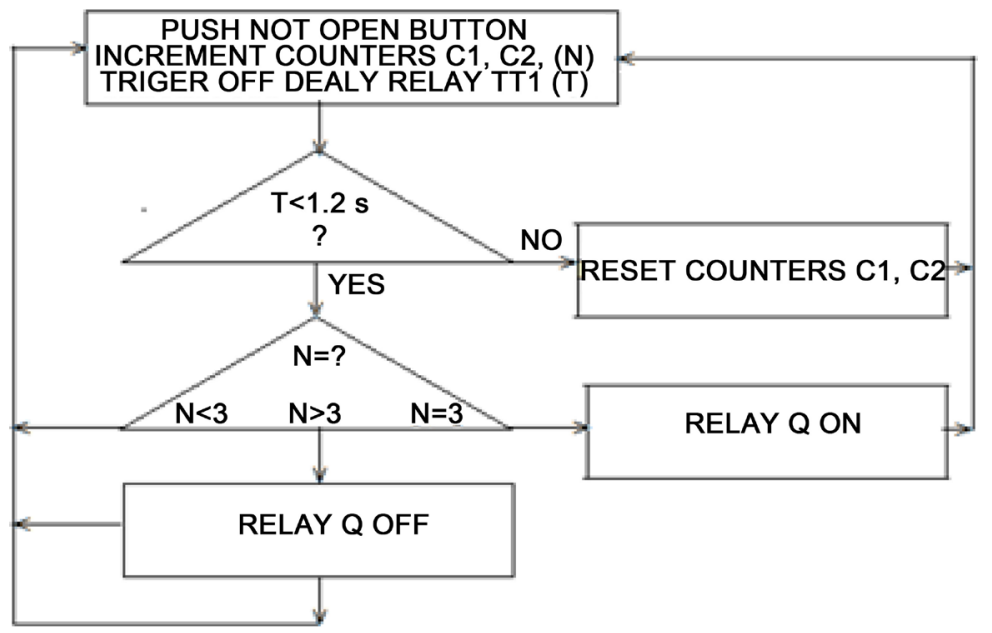

(a)

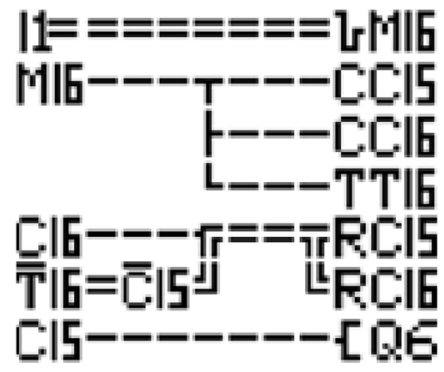

(b)

Figure 5. Distance control algorithm. (a) Logic diagram; (b) Ladder program.

remains in OFF position. There are three situations if the cable is cut or shortcut, too. This principle can be used to design a standalone device with a minimum hardware like a simple microcontroller or a VLSI solution [19]. For the case of using PLC, this solution is very comfortable [20] [21] [22]. In Figure 5 (b) the algorithm is simulated and verified using a ladder program on a Moeller PLC.

\section{Application Example}

Consider the case of up/down elevators which extract the materials from a mining underground using two cages running in alternative mode [23]. In the underground there is a potentially explosive atmosphere and requires anti-explosive PLCs control the equipment [24]. The main requirements are:

- Automated or manual regime;

- Two inputs (I1, I2) to initiate start/stop for left/right;

- Two outputs control (Q1, Q2) for up/down;

- The combinations of logic states I1, I2 assure 4 regimes as shown in Table 1;

- Going in any sense and for pause is set before using TT1, TT2 and TT3, TT4 timers;

- The controlled sense is interlocked.

In Figure 6 the model of logic control and simulation results is presented, 
Table 1. Going regime.

\begin{tabular}{cccc}
\hline States & I1 & I2 & Going regime \\
\hline 1 & 0 & 0 & Pause \\
2 & 1 & 0 & Manual/right \\
3 & 0 & 1 & Manual/left \\
4 & 1 & 1 & Automat left/right \\
\hline
\end{tabular}

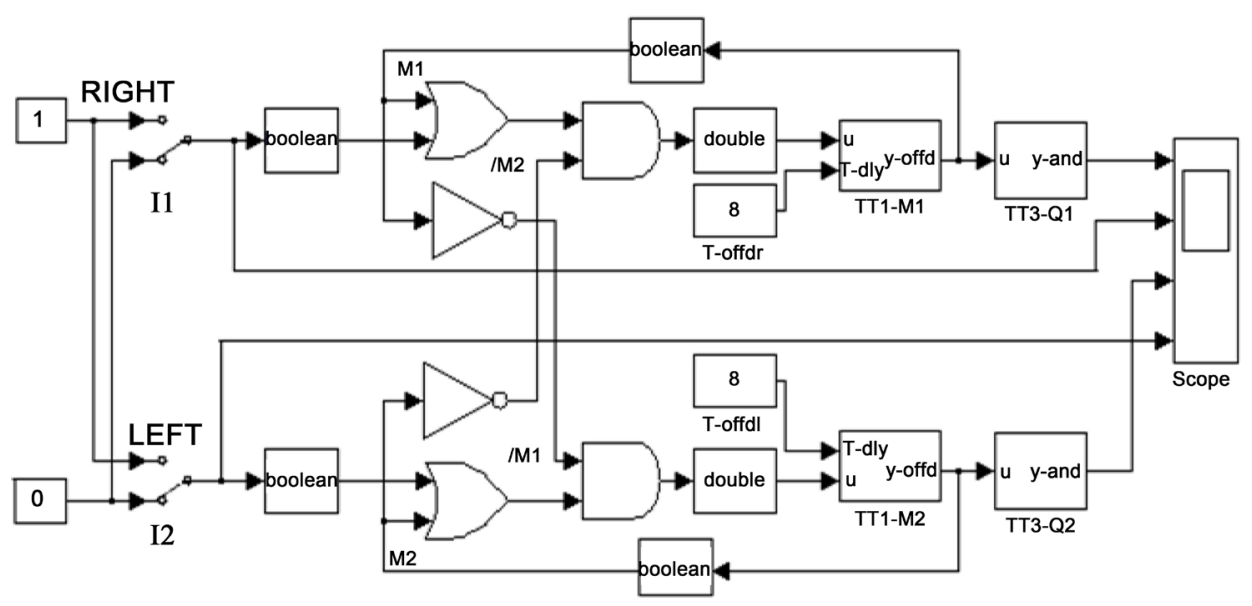

(a)

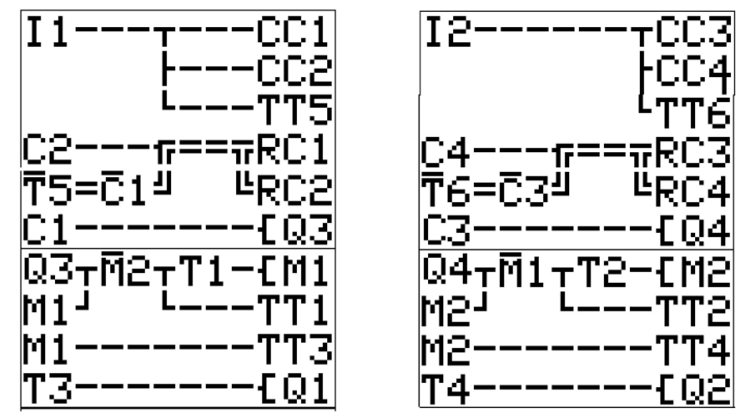

(b)

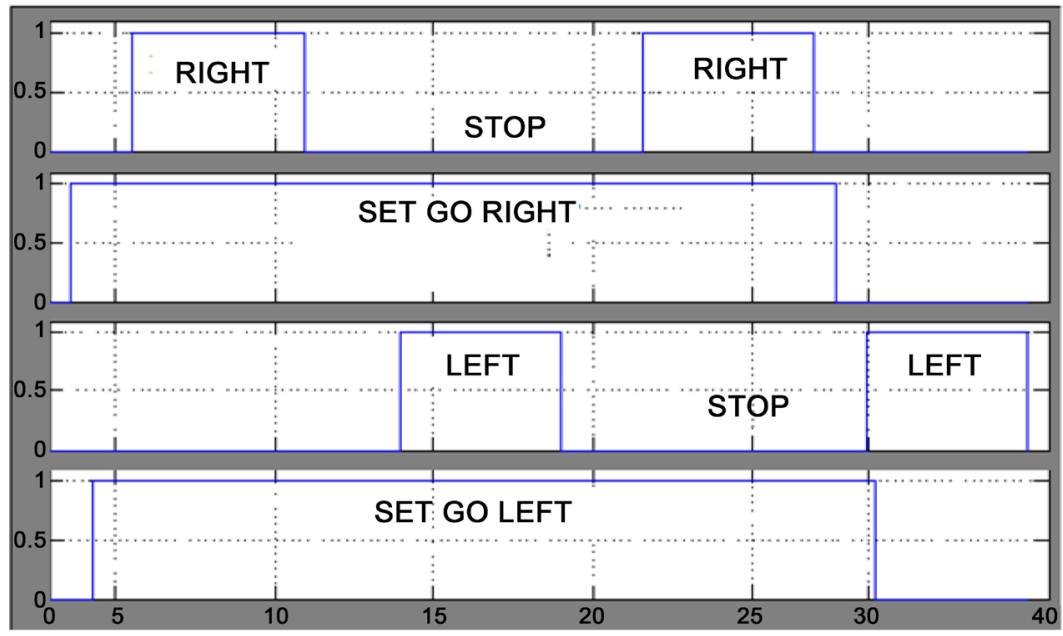

(c)

Figure 6. Logic model, simulation results and ladder program for a mining elevator. (a) Logic model; (b) Ladder program; (c) Simulation results. 


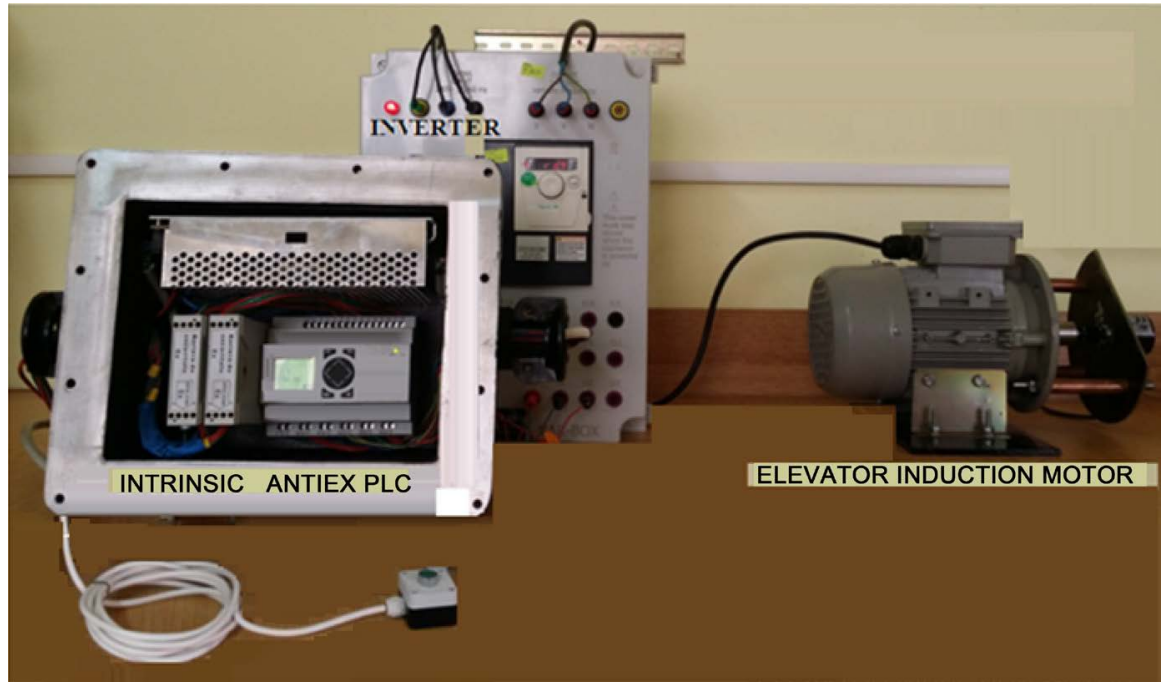

Figure 7. Example of elevator controller using anti-explosive PLC with intrinsic safety button.

where the I1, I2 must be long distance intrinsic distance control with positive security and Ladder program for PLC.

In Figure 7 we presented the experimental laboratory model for elevator controller using anti-explosive PLC with intrinsic safety button.

\section{Conclusions}

Presence of some inflammable substances like butane, propane, acetylene, methane, petrol fuels, oils, chemical solvents and inflammable dusty of coal, wood, cereals, plastic materials etc., transforms a normal location in one with a potential explosive atmosphere.

Presence of some ignition energy sources transforms a potential explosive atmosphere in a location with risk of explosions. This is a hazardous area and must use the special control equipment like that of intrinsic safety.

A very useful solution is by software approach which can be easy implemented if the control is done by microprocessors or PLC.

In the final of this paper an intrinsic control button is implemented and tested. This uses a safety optic isolator barrier and positive security, based on software design solution.

\section{References}

[1] Cioclea, D., Toth, I., Lupu, C., Jurca, L. and Gligor, C. (2008) Coal Susceptibility to Spontaneous Combustion. INSEMEX Publishing House, Petrosani.

[2] Cioclea, D. (2008) Methods and Manners for Preventing and Fighting against Spontaneous Combustions When Applying the Undermined Coal Bed Exploitation Method. INSEMEX Publishing House, Petrosani.

[3] Darie, M., Burian, S., Ionescu, J., Csaszar, T., Moldovan, L. and Andriş, A. (2010) Modern Prediction Methods in the Monitoring Process of Security Parameters. WSEAS Transactions on Systems, 9, 713-723. 
[4] Gfhn, J., Ilias, N., Andras, I., Radu, S., Petrar, A., Hoara, M. and Teseleanu, G. (2010) Mechanized Underground Coal Mining to Increase Safety and Productivity. Proceedings of the International Conference on Risk Management, Assessment and Migration (RIMA'10), Bucharest, 20-22 April 2010, 123-125.

[5] Dhillon, B.S. (2008) Mining Equipment Reliability, Maintainability, and Safety. Springer Series in Reliability Engineering. Springer-Verlag, London.

[6] Leroux, P. (2005) The Operator's Viewpoint of the ATEX Directive 94/9/EC New Regulations and Rules for Explosive Atmospheres in Europe. Industry Applications Society 52nd Annual Conference on Petroleum and Chemical Industry, 12-14 September 2005, 367-376. https://doi.org/10.1109/PCICON.2005.1524574

[7] Csaszar, T., Păsculescu, D., Burian, S., Darie, M. and Ionescu, J. (2012) Method of Assessment for Energy Limited Supply Sources, Designed for Use in Potentially Explosive Atmospheres. Environmental Engineering and Management Journal, 11, 1281-1285.

[8] Bottrill, G., Cheyne, D. and Vijayaraghavan, G. (2005) Practical Electrical Equipment and Installations in Hazardous Areas. Elsevier, Amsterdam.

[9] Leba, M., Pop, E., Sochirca, B. and Vanvu, P. (2009) Modeling, Simulation and Design of the Intrinsic Protection Using Safety Barrier. Proceeding of the 8 th WSEAS International Conference on CIRCUITS, SYSTEMS, ELECTRONICS, CONTROL AND SIGNAL PROCESSING (CSECS09), Perto de la Cruz, Tenerife, 14-16 December 2009.

[10] Pop, E. (1993) Automation in the Mining Industry. EDP, Bucuresti.

[11] Liu, H., Huang, C. and Xiao, F. (2011) Research on Monitor System of Distant Coal Mine Gas Based on Labview. Electrical Power Systems and Computers, Nanchang, 20-22 June 2011, 457-461. https://doi.org/10.1007/978-3-642-21747-0_57

[12] Dunning, G. (2006) Introduction to Programmable Logic Controller. Elsevier, Amsterdam.

[13] Barbu, I.C., Pop, E. and Leba, M. (2009) Microsisteme energetice durabile regenerative. Editura Didactică și Pedagogica, Bucuresti.

[14] Pop, E. and Bubatu, R. (2012) Systems Theory. Education through e-Learning. Editura Universitas.

[15] Pop, E. (2013) Kalman Filter Design, Modeling, Simulation and Practical Applications. Proccedings of the 12th International Conference on Applied Computer and Applied Computational Science, Kuala Lumpur, 2-4 April 2013, 48-52.

[16] PNCDI-CEEx Project (2005) Development of Hardware and Software Structures in Accordance with European Requirements on the Safety Integrity Level SIL in the Field of Primary Extractions and Processing of Oil and Gas Aimed for Diminishing Environmental Impact. CEEx Research Program.

[17] Pop, E. and Patrascoiu, N. (2013) Practically Algorithm, Modeling and Simulation of Luenberger Observer. Proccedings of the 12th International Conference on Applied Computer and Applied Computational Science, Kuala Lumpur, 2-4 April 2013, 53-58.

[18] Pop, E. and Patrascoiu, N. (2013) Simulation and Design Algorithm for Identifiers. Applications. Proccedings of the 12 th International Conference on Applied Computer and Applied Computational Science, Kuala Lumpur, 2-4 April 2013, 59-64.

[19] Avram, A., Pop, E. and Barbu, C. (2010) VLSI Embedded Solution for Multi-Drive 
Conveyors Control. Proceedings of the International Conference on Applied Computer Science, Iwate, 4-6 October 2010, 593-596.

[20] Poantă, A., Dojcsar, D. and Sochirca, B. (2009) System Command of a Pump Instalation Based on a Programmable Controller. Revista Minelor, 15, 15-18.

[21] Dobra, R., Marc, Gh., Ungur, A.-R., Ilcea, G., Radu, S. and Popescu, R.-M. (2015) Programmable Automation Controller for Industrial Process Control. International Electrical \& Electronic Engineering and Technologies Conference, Istambul, 2-3 October 2015, 142-149.

[22] Ilcea, G., Dobra, R., Păsculecu, D. and Buică, G. (2014) Decision Support System Based on Fiber Optic Technology Applicable to Mining Industry. Proceedings of International Conference on Circuits, Systems, Signal and Telecommunications, Tenerife, 10-12 January 2014, 148-151.

[23] Bogbanffy, L., Pop, E. and Ilcea, G. (2016) HIL Simulation as Rapid Prototyping Method in Control Engineering. International Journal of Control Systems and Robotics, 1, 133-138.

[24] Pinto, V., Silviano, R. and Martins, J.F. (2007) PLC Controlled Industrial Processes On-Line Simulato. IEEE International Symposium on Industrial Electronics, Vigo, 4-7 June 2007, 2954-2957. 